\title{
Otimização amostral de atributos de latossolos considerando aspectos solo-relevo
}

\author{
Sampling optimization of oxisol attributes considering soil-relief relationship
}

\author{
Zigomar Menezes de Souza ${ }^{1}$ José Marques Júnior ${ }^{2}$ Gener Tadeu Pereira ${ }^{3}$ Rafael Montanari ${ }^{4}$
}

\section{RESUMO}

O custo de amostragem do solo para caracterizar a variabilidade espacial de atributos químicos e físicos é um problema em agricultura de precisão. O objetivo deste trabalho foi utilizar a forma da paisagem como critério auxiliar na otimização do esquema amostral, a fim de estimar os atributos químicos e físicos de latossolos em áreas sob cultivo de canade-açúcar. $O$ solo foi amostrado na profundidade de 0,0-0,2m nos pontos de cruzamento de uma malha, com intervalos regulares de $10 \mathrm{~m}$, perfazendo um total de 100 pontos. Todos os atributos químicos e físicos tiveram mais de $84 \%$ dos pontos plotados na pedoforma côncava e convexa em relação aos da pedoforma linear. A aplicação do programa Sanos $0.1 \mathrm{na}$ malha amostral permitiu verificar que, na pedoforma côncava e convexa, há maior variabilidade espacial para os atributos químicos e físicos do solo, em comparação à pedoforma linear.

Palavras chave: Saccharum officinarum, atributos químicos e físicos, amostragem do solo, variabilidade espacial.

\section{ABSTRACT}

The cost of sampling for spatial variability characterization of soil chemical and physical attributes is a fundamental problem in precision agriculture. The objective of this work was to use the landscape form as an auxiliary criterion for sampling optimization in an Oxisol under sugarcane cultivation, aiming at the estimation of their chemical and physical attributes. Soil samples were collected in the depths of $0.0-0.2 \mathrm{~m}$ in the intersections of a $10 \mathrm{~m}$ regular interval grid, comprising a total of 100 points. All chemical and physical attributes had more than $84 \%$ of the points plotted in the concave and convex landforms compared to the linear landform. Larger spatial variability in the soil of chemical and physical attributes was observed in the concave landform than in the linear one according to analysis performed with the program Sanos 0.1 .

Key words: Saccharum officinarum, chemical and physical attributes, soil sampling, spatial variability.

\section{INTRODUÇÃO}

As estratégias de amostragem são importantes para mapear a variabilidade espacial dos solos, pois só a partir de sua modelagem é possível gerar mapas mais consistentes e com precisão. Assim, o estudo dos aspectos da amostraaagem do solo, a fim de subsidiar a tomada de decisão para a utilização e recomendação destas técnicas em ambientes distintos tem sido preocupação constante dos pesquisadores (GROENIGEN et al., 1999; LARK, 2000).

A eficácia das estratégias de amostragem do solo pode ser aumentada com a incorporação de um modelo de variabilidade espacial. SOUZA et al. (1997) relataram que o conhecimento do alcance da dependência espacial dos atributos do solo pode ser um critério para definir o intervalo das amostragens. Porém, estes valores dependem da escala, da intensidade de coleta e do manejo da área. Portanto, a característica do relevo, como a forma, pode ser de extrema importância na definição de esquemas de amostragem, bem como na definição de zonas de manejo físico e químico do solo. Esta premissa pode

${ }^{1}$ Departamento de Solos e Adubos, Faculdade de Ciências Agrárias e Veterinárias (FCAV), Universidade Estadual de São Paulo (UNESP). Via de acesso Prof. Paulo Donato Castellane s/n, 14870-900, Jaboticabal, SP, Brasil. E-mail:zigomarms@yahoo.com.br. Autor para correspondência.

2Departamento Solos e Adubos, FCAV/UNESP, Jaboticabal, SP, Brasil. E-mail:marques@fcav.unesp.br.

${ }^{3}$ Departamento de Ciências Exatas, FCAV/UNESP, Jaboticabal, São Paulo, Brasil. E-mail:genertp@fcav.unesp.br.

${ }^{4}$ Departamento Solos e Adubos, FCAV/UNESP, Jaboticabal, São Paulo, Brasil. E-mail:montana@fcav.unesp.br. 
ser aplicada às técnicas de simulação de resultados (GROENIGEN et al., 1999), possibilitando a otimização do número de amostras e transferência de informação para ambientes similares.

Estudando as correlações das produções de milho e soja com a posição topográfica e atributos químicos do solo, KRAVCHENCO \& BULLOCK (2000) verificaram que a combinação das características topográficas explicou entre 6 a 54\% da variabilidade da produtividade do milho e da soja, porém, quando combinou-se propriedades topográficas e químicas, foram explicados 10 a $78 \%$ da variabilidade da produtividade dessas culturas. Nesse estudo, foram encontradas baixa produtividade nas posições de elevado declive e alta produtividade nas áreas de baixo declive.

O comportamento diferenciado dos atributos dos solos em diferentes locais da paisagem pode ser entendido pela caracterização da variabilidade espacial deles mediante técnicas de geoestatística, identificando locais específicos na paisagem. Estudos mostram que, em latossolos, em áreas de formas côncavas e convexas, independentes do histórico de manejo, há mais variabilidade de atributos químicos e físicos do que em áreas de formas lineares (SOUZA et al., 2003; SOUZA et al., 2004). Isso implica maior número de subamostras naquelas áreas. Portanto, na avaliação da variabilidade espacial, o espaçamento com intervalos menores é necessário em áreas côncavas e convexas, sendo que uma das maneiras de avaliar esta premissa é mediante as técnicas de otimização de amostragem, baseadas em um algoritmo de simulação espacial (GROENIGEN et al., 1999).

O objetivo deste trabalho foi utilizar a forma da paisagem como critério auxiliar à otimização do esquema amostral na estimação dos atributos químicos e físicos de latossolos, em áreas sob cultivo de canade-açúcar.

\section{MATERIAL E MÉTODOS}

A área de estudo localiza-se no nordeste do Estado de São Paulo, no município de Guariba. As coordenadas geográficas são $21^{\circ} 19^{\prime}$ de latitude sul e $48^{\circ} 13^{\prime}$ de longitude oeste e a altitude média é de $640 \mathrm{~m}$. O clima da região, segundo a classificação de Köppen, é do tipo mesotérmico com inverno seco (Cwa), com precipitação média de $1.400 \mathrm{~mm}$ e chuvas concentradas no período de novembro a fevereiro.

O relevo é predominantemente suave ondulado, com declividades médias variando de 3 a $8 \%$. A área experimental está sob cultivo de cana-de-açúcar há mais de 30 anos. $\mathrm{O}$ solo da área foi classificado como Latossolo Vermelho eutroférrico, textura muito argilosa (LVef) (EMBRAPA, 1999). Na área em estudo, foi adotado o seguinte manejo: no primeiro plantio e a cada 6 anos, quando da renovação, foram feitas duas gradagens pesadas e abertura de sulcos com sulcador, aplicando calcário para elevar a saturação de base a $60 \%$. Realizou-se, no plantio, uma adubação de $1.400 \mathrm{~kg}$ $\mathrm{ha}^{-1}$, com adubo líquido, com a seguinte fórmula: 610-8 (N- $\left.\mathrm{P}_{2} \mathrm{O}_{5}-\mathrm{K}_{2} \mathrm{O}\right)$, e adubação de manutenção de $1.500 \mathrm{~kg} \mathrm{ha}^{-1}$, com adubo líquido, com a seguinte fórmula 11-4-8.

De acordo com o modelo de TROEH (1965), classificou-se a curvatura e o perfil das formas do terreno, no terço inferior da encosta, em dois compartimentos: I e II (Figura 1). No compartimento I, a forma do relevo é basicamente linear, e o compartimento II apresenta curvaturas côncavas e convexas. O solo foi amostrado com trado em outubro 2002, na entrelinha da cultura após a colheita, nos pontos de cruzamento de uma malha, georeferenciados, com intervalos regulares de $10 \mathrm{~m}$, na profundidade de $0,0-0,2 \mathrm{~m}$, com dimensão de $100 \times 100 \mathrm{~m}$, totalizando 100 pontos, em uma área de 1 ha. $\mathrm{O}$ pH $\left(\mathrm{CaCl}_{2}\right)$ e os teores de $\mathrm{Ca}, \mathrm{K}$ e o $\mathrm{P}$ disponível foram determinados conforme RAIJ et al. (2001). Com base nos resultados das análises químicas, determinaram-se a capacidade de troca catiônica (CTC efetiva) e a saturação por bases (V\%).

Para determinação dos atributos físicos, foram abertas 100 trincheiras de $0,60 \mathrm{~m}$ de profundidade ( $0,3 \times 0,3 \mathrm{~m}$ de largura). A porosidade do solo (total, macro e microporosidade) foi obtida de amostras indeformadas coletadas com anéis volumétricos de $0,03 \mathrm{~m}$ de altura e $0,048 \mathrm{~m}$ de diâmetro, saturadas por 48 horas em bandeja, com água até dois terços da altura do anel. Após o período de saturação, as amostras foram drenadas no potencial equivalente a $-0,006 \mathrm{MPa}$, utilizando uma mesa de tensão (EMBRAPA, 1997). Nas mesmas amostras, determinou-se a densidade do solo, utilizando-se o método do volume conhecido (EMBRAPA, 1997). A resistência do solo à penetração foi determinada utilizando um penetrômetro de impacto, modelo IAA/Planalsucar com índice de cone de $30^{\circ}$, conforme STOLF (1991). A fração argila foi determinada pelo método da pipeta (EMBRAPA, 1997).

Foram realizadas as análises estatísticas descritivas dos dados obtidos e a hipótese de normalidade pelo teste de Kolmogorov-Smirnov, por meio do programa SAS (SCHLOTZHAVER \& LITTELL, 1997). Determinaram-se também o número de subamostras necessárias para compor uma amostra composta e estimar o valor médio das variáveis usando a fórmula descrita por CLINE (1944): 


$$
\mathrm{n}=\left(\frac{\mathrm{t}_{\alpha} \cdot \mathrm{CV}}{\mathrm{D}}\right)^{2}
$$

em que $n$ é o número mínimo de amostras; $t \alpha$ é o valor do teste $\mathrm{t}$ de Student para o nível de probabilidade de $95 \%$; $C V$ é o coeficiente de variação; $D$ é a porcentagem de variação em torno da média (5\%).

Cada atributo químico e físico foi submetido ao ajuste de modelos matemáticos para a definição dos semivariogramas pelo programa $\mathrm{GS}^{+}$(ROBERTSON, 1998) e à técnica de interpolação de dados (krigagem) pelo programa SURFER (1999). A análise do grau de dependência espacial dos atributos foi realizada segundo CAMBARDELLA et al. (1994), em que são considerados de dependência espacial forte os semivariogramas que têm um efeito pepita menor ou igual a $25 \%$ do patamar, moderada entre 25 e $75 \%$, e fraca quando for maior que $75 \%$. Considerou-se o alcance obtido por meio do semivariograma para definir o número de subamostras necessárias para avaliar os atributos químicos e físicos. Para garantir a dependência espacial, assumiu-se que os pontos de amostragem deveriam ser coletados a uma distância equivalente à metade do alcance, o que foi realizado no plano amostral delineado.

A otimização dos atributos químicos e físicos do solo foi obtida por meio do programa Sanos for
Windows 0.1, o qual se baseia em um algoritmo de simulação espacial (GROENIGEN et al., 1999). Este algoritmo utiliza vários critérios quantitativos de otimização e o utilizado neste trabalho foi o da minimização da variância da krigagem ordinária e o do semivariograma estimado.

\section{RESULTADOS E DISCUSSÃO}

Os resultados referentes ao teste Kolmogorov-Smirnov indicaram normalidade para K, CTC, V\%, densidade do solo, macroporosidade, microporosidade e resistência do solo à penetração (Tabela 1). Mais importante que a normalidade é que os semivariogramas apresentem patamares bem definidos e que a distribuição não apresente caudas muito alongadas, o que poderia comprometer as estimativas da krigagem, as quais são baseadas nos valores médios (ISAAKS \& SRIVASTAVA, 1989).

Com base na fórmula proposta por CLINE (1944), o valor de $\mathrm{pH}, \mathrm{CTC}, \mathrm{V} \%$, argila, densidade do solo, porosidade total e microporosidade, por possuírem baixo $\mathrm{CV}$ (Tabela 1), podem ser estimados com menor número de subamostras, concordando com os resultados obtidos por SILVEIRA \& CUNHA(2002). Em relação aos atributos $\mathrm{Ca}, \mathrm{P}, \mathrm{K}$, macroporosidade $\mathrm{e}$ resistência do solo à penetração, observou-se a necessidade de um maior número de subamostras a

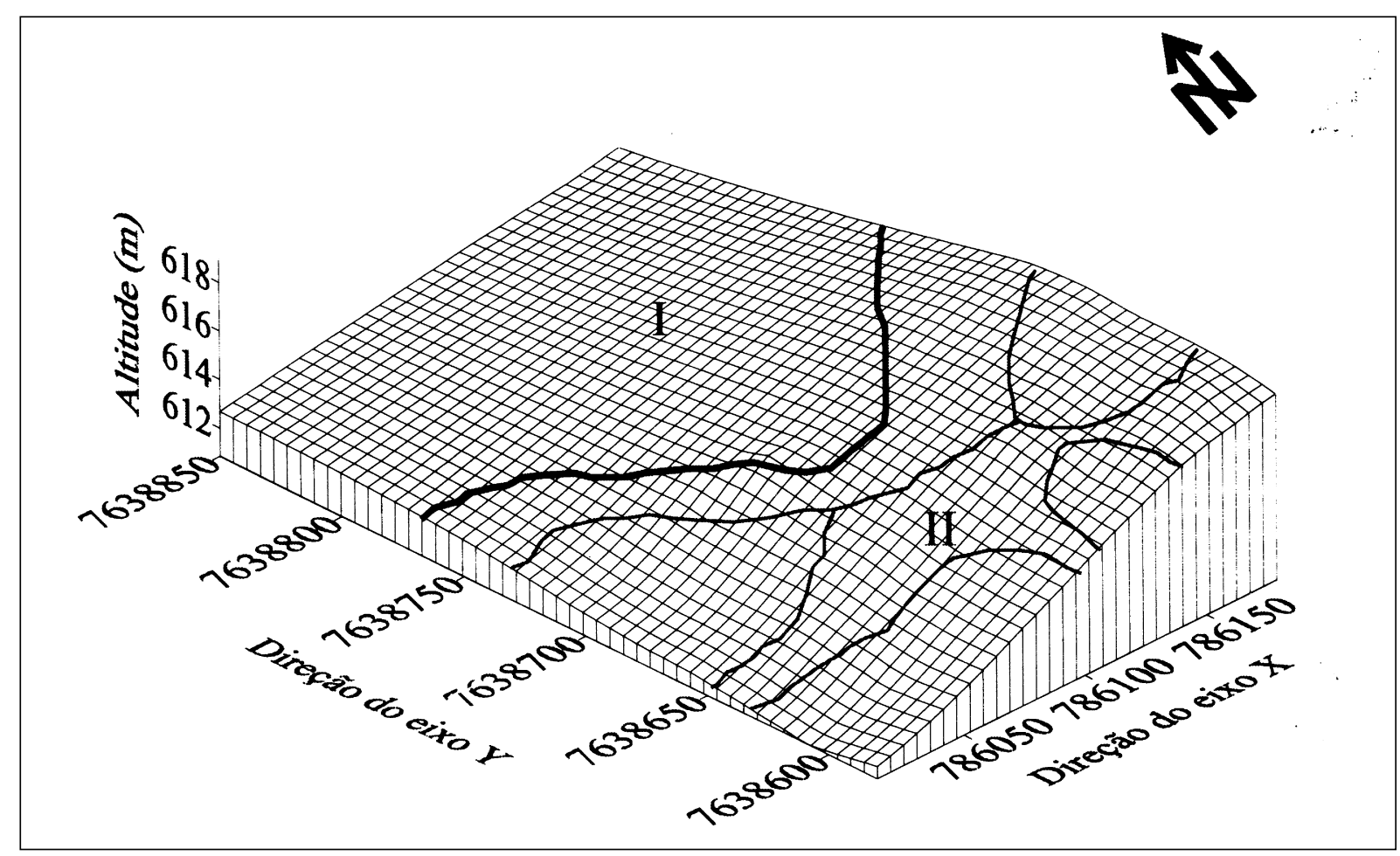

Figura 1 - Modelo de elevação digital da área de estudo, com compartimentos I e II identificados.

Ciência Rural, v.36, n3, mai-jun, 2006. 
Tabela 1 - Valores médios, mínimos, máximos, coeficiente de variação $(\mathrm{CV})$ e número mínimo de subamostras necessários para estimar os valores de atributos químicos e físicos do solo na profundidade de $0,0-0,2 \mathrm{~m}$.

\begin{tabular}{|c|c|c|c|c|c|c|c|}
\hline \multirow{2}{*}{ Atributo } & \multicolumn{5}{|c|}{ Estatística } & \multicolumn{2}{|c|}{ Número de subamostras } \\
\hline & Média & Mínimo & Máximo & $\mathrm{CV}(\%)$ & ${ }^{1} \mathrm{~d}$ & Fórmula de Cline & Alcance \\
\hline & \multicolumn{7}{|c|}{ Atributo químico } \\
\hline $\mathrm{pH}\left(\mathrm{CaCl}_{2}\right)$ & 4,8 & 4,0 & 5,6 & 5,4 & 0,10 & 3 & 25 \\
\hline Cálcio $\left(\mathrm{mmol}_{\mathrm{c}} \mathrm{dm}^{-3}\right)$ & 25,9 & 9,0 & 44,0 & 33,5 & 0,08 & 181 & 64 \\
\hline Fósforo $\left(\mathrm{mg} \mathrm{dm}^{-3}\right)$ & 22,5 & 6,2 & 39,4 & 40,5 & 0,11 & 265 & 64 \\
\hline Potássio $\left(\mathrm{mmol}_{\mathrm{c}} \mathrm{dm}^{-3}\right)$ & 3,1 & 0,7 & 6,5 & 33,9 & $0,06^{\mathrm{ns}}$ & 185 & 36 \\
\hline $\mathrm{CTC}\left(\mathrm{mmol}_{\mathrm{c}} \mathrm{dm}^{-3}\right)$ & 85,7 & 66,0 & 106,6 & 17,8 & $0,04^{\mathrm{ns}}$ & 51 & 16 \\
\hline \multirow[t]{2}{*}{ Saturação por bases (\%) } & 45,4 & 27,0 & 63,0 & 21,9 & $0,08^{\mathrm{ns}}$ & 77 & 25 \\
\hline & \multicolumn{7}{|c|}{ Atributo físico } \\
\hline $\operatorname{Argila}\left(\mathrm{g} \mathrm{kg}^{-1}\right)$ & 622 & 590 & 660 & 2,9 & 0,12 & 2 & 36 \\
\hline Densidade do solo $\left(\mathrm{kg} \mathrm{dm}^{-3}\right)$ & 1,38 & 1,16 & 1,65 & 7,5 & $0,04^{\mathrm{ns}}$ & 9 & 100 \\
\hline Porosidade total $\left(\mathrm{m}^{3} \mathrm{~m}^{-3}\right)$ & 0,51 & 0,45 & 0,55 & 17,5 & 0,10 & 49 & 64 \\
\hline Macroporosidade $\left(\mathrm{m}^{3} \mathrm{~m}^{-3}\right)$ & 0,15 & 0,03 & 0,26 & 28,5 & $0,05^{\mathrm{ns}}$ & 131 & 100 \\
\hline Microporosidade $\left(\mathrm{m}^{3} \mathrm{~m}^{-3}\right)$ & 0,37 & 0,19 & 0,50 & 19,1 & $0,08^{\text {ns }}$ & 59 & 64 \\
\hline Resistência do solo (MPa) & 4,4 & 1,15 & 5,60 & 38,7 & $0,07^{\mathrm{ns}}$ & 241 & 100 \\
\hline
\end{tabular}

${ }^{1} \mathrm{~d}=$ teste de normalidade, ${ }^{\text {ns }}$ não significativo pelo teste de Kolmogorov-Smirnov.

serem coletadas na área para a percentagem de variação de $5 \%$ em torno da média (Tabela 1 ).

Utilizando-se o procedimento de se coletar 20 subamostras para compor uma amostra composta para os atributos químicos, como proposto por RAIJ et al. (1997), os resultados obtidos mostraram que o $\mathrm{pH}$ estaria dentro do recomendado, para uma variação de $5 \%$ em torno da média. Os teores de $\mathrm{Ca}, \mathrm{P}, \mathrm{K}$ e os valores da CTC e de V\% não atenderiam ao número mínimo de subamostras recomendadas. Essa discrepância também foi observada quando se utiliza o alcance para estimar o número de subamostras (Tabela 1). Porém, SANTOS \& VASCONCELLOS (1987) afirmam que os atributos com baixo CV não são adequados para determinar o número de amostras de solos requeridas para se avaliar com precisão o nível de fertilidade da área, tendo em vista a grande variabilidade encontrada para os atributos como $\mathrm{P}, \mathrm{K}, \mathrm{Mg}$ e $\mathrm{Ca}$, os quais são altamente influenciados pelo manejo.

Todos os atributos analisados apresentaram dependência espacial (Tabela 2). O modelo esférico ajustou-se à semivariância estimada de todos os atributos químicos, com exceção do $\mathrm{P}$, cujos resultados se ajustaram ao modelo exponencial. A semivariância estimada de todos os atributos físicos ajustou-se ao modelo esférico. Os atributos químicos e físicos apresentaram coeficiente de determinação $\left(\mathrm{R}^{2}\right)$ acima de 0,88 , ou seja, $88 \%$ da variabilidade existente nos valores da semivariância estimada é explicada pelos modelos ajustados.
$\mathrm{A}$ análise da relação $\mathrm{C}_{0} /\left(\mathrm{C}_{0}+\mathrm{C}_{1}\right)$ dos atributos químicos e físicos do solo mostrou que os atributos $\mathrm{Ca}$, densidade do solo, porosidade total, macroporosidade, microporosidade e resistência do solo à penetração apresentaram grau de dependência espacial forte, segundo a classificação proposta por CAMBARDELLA et al. (1994), e os atributos pH, P, K, CTC, V\% e argila apresentaram grau de dependência espacial moderada (Tabela 2).

$\mathrm{O}$ alcance é uma medida importante no planejamento e na avaliação experimental, já que pode auxiliar na definição de procedimento de amostragem (McBRATNEY \& WEBSTER, 1983). Este parâmetro representa a distância em que os pontos amostrais estão correlacionados. Houve dois grupos de alcances para os atributos em estudo, aqueles com variação entre $20 \mathrm{~m}$ a $30 \mathrm{~m}$ (densidade do solo, macroporosidade, resistência do solo à penetração, porosidade total, microporosidade, $\mathrm{P}$ e $\mathrm{Ca}$ ) e o grupo com alcance variando entre $35 \mathrm{~m}$ a $60 \mathrm{~m}$ (argila, $\mathrm{K}, \mathrm{V} \%$, pH e CTC) (Tabela 2). O manejo do solo utilizado na área ao longo do tempo, como aplicações de fertilizantes e calcário, pode ter contribuído para maior homogeneização, tendo como conseqüência o aumento do alcance de dependência espacial dos atributos químicos, com exceção de Ca e P. Isso se deveu provavelmente ao calcário ter sido aplicado a lanço e a baixa mobilidade do $\mathrm{P}$ ter contribuído para uma maior heterogeneidade destes atributos diminuindo o alcance da dependência espacial. 
Tabela 2 - Avaliação geoestatística de atributos químicos e físicos do solo nas diferentes pedoformas estudadas.

\begin{tabular}{|c|c|c|c|c|c|c|}
\hline Atributos & Modelo & Efeito pepita $\left(\mathrm{C}_{0}\right)$ & Patamar $\mathrm{C}_{0}+\mathrm{C}_{1}$ & Alcance (a) & $\mathrm{C}_{0} /\left(\mathrm{C}_{0}+\mathrm{C}_{1}\right)$ & $\mathrm{R}^{2}$ \\
\hline & & & Atributo químice & & & \\
\hline $\mathrm{pH}\left(\mathrm{CaCl}_{2}\right)$ & Esférico & 0,02 & 0,07 & 48,1 & 29 & 98 \\
\hline Cálcio $\left(\mathrm{mmol}_{\mathrm{c}} \mathrm{dm}^{-3}\right)$ & Esférico & 9,9 & 47,6 & 28,7 & 21 & 93 \\
\hline Fósforo $\left(\mathrm{mg} \mathrm{dm}^{-3}\right)$ & Exponencial & 9,3 & 32,4 & 27,9 & 28 & 88 \\
\hline Potássio $\left(\mathrm{mmol}_{\mathrm{c}} \mathrm{dm}^{-3}\right)$ & Esférico & 0,74 & 1,5 & 41,0 & 50 & 94 \\
\hline CTC $\left(\mathrm{mmol}_{\mathrm{c}} \mathrm{dm}^{-3}\right)$ & Esférico & 61,1 & 125,2 & 56,2 & 49 & 98 \\
\hline \multirow[t]{2}{*}{ Saturação por bases (\%) } & Esférico & 39,3 & 93,4 & 47,5 & 42 & 99 \\
\hline & \multicolumn{6}{|c|}{ Atributo físico } \\
\hline Argila $\left(\mathrm{g} \mathrm{kg}^{-1}\right)$ & Esférico & 106 & 314 & 35 & 34 & 98 \\
\hline Densidade do solo $\left(\mathrm{kg} \mathrm{dm}^{-3}\right)$ & Esférico & 0,002 & 0,008 & 20 & 25 & 90 \\
\hline Porosidade total $\left(\mathrm{m}^{3} \mathrm{~m}^{-3}\right)$ & Esférico & 0,0001 & 0,0008 & 27 & 12 & 97 \\
\hline Macroporosidade $\left(\mathrm{m}^{3} \mathrm{~m}^{-3}\right)$ & Esférico & 0,0007 & 0,004 & 20 & 18 & 92 \\
\hline Microporosidade $\left(\mathrm{m}^{3} \mathrm{~m}^{-3}\right)$ & Esférico & 0,0004 & 0,002 & 27 & 20 & 90 \\
\hline Resistência do solo (MPa) & Esférico & 0,09 & 0,96 & 20 & 9 & 96 \\
\hline
\end{tabular}

A utilização do alcance do semivariograma diminuiu o número de amostras a serem coletadas para avaliação de todos os atributos químicos, com exceção do $\mathrm{pH}$, em relação à fórmula de Cline (Tabela 3 ). Entretanto, com os atributos físicos, isso somente ocorreu com a macroporosidade e com a resistência do solo à penetração, pois o número de amostras para a porosidade total e a microporosidade foram próximos aos obtidos com a fórmula de CLINE (Tabela 3). Esses resultados corroboram os obtidos por McBRATNEY \& WEBSTER (1983) e SOUZA et al. (1997), os quais afirmam que o uso do alcance do semivariograma de

Tabela 3 - Número de pontos plotados no compartimento I (Linear) e no compartimento II (côncavo e convexo) calculado pelo programa Sanos 0.1 (fórmula de CLINE (1944) com variação de $5 \%$ em torno da média e alcance do semivariograma), na profundidade de $0,0-0,2 \mathrm{~m}$.

\begin{tabular}{|c|c|c|c|c|c|c|}
\hline \multirow{2}{*}{ Atributos do solo } & \multicolumn{2}{|c|}{ Número total de pontos } & \multicolumn{2}{|c|}{ Compartimento I } & \multicolumn{2}{|c|}{ Compartimento II } \\
\hline & Fórmula de Cline & Alcance & Fórmula de Cline & Alcance & Fórmula de Cline & Alcance \\
\hline
\end{tabular}

Atributo químico

\begin{tabular}{|c|c|c|c|c|c|}
\hline $\mathrm{pH}$ & 3 & 25 & 0 & 3 & 3 \\
\hline Cálcio & 181 & 64 & 16 & 6 & 165 \\
\hline Fósforo & 265 & 64 & 18 & 7 & 247 \\
\hline Potássio & 185 & 36 & 19 & 5 & 166 \\
\hline CTC & 51 & 16 & 8 & 1 & 43 \\
\hline Saturação por bases & 77 & 25 & 7 & 2 & 70 \\
\hline
\end{tabular}

\begin{tabular}{|c|c|c|c|c|c|c|}
\hline \multirow[b]{2}{*}{ Argila } & \multicolumn{6}{|c|}{ Atributo físico } \\
\hline & 2 & 36 & 0 & 2 & 2 & 34 \\
\hline Densidade do solo & 9 & 100 & 1 & 14 & 8 & 86 \\
\hline Porosidade total & 49 & 64 & 5 & 5 & 44 & 56 \\
\hline Macroporosidade & 131 & 100 & 16 & 10 & 115 & 90 \\
\hline Microporosidade & 59 & 64 & 7 & 3 & 52 & 61 \\
\hline Resistência do solo & 241 & 100 & 17 & 11 & 224 & 89 \\
\hline
\end{tabular}

Ciência Rural, v.36, n3, mai-jun, 2006. 
atributos do solo pode reduzir o número de amostras em relação ao uso dos procedimentos amostrais definidos na estatística clássica. McBRATNEY \& WEBSTER (1983) afirmam que a eficácia da estratégia de amostragem do solo pode ser aumentada com a incorporação de um modelo de variabilidade espacial.

A indicação de maior concentração de pontos pelo programa Sanos 0.1 revela os locais de maior variabilidade espacial dos atributos químicos e físicos avaliados (Tabela 3, Figuras 2 e 3). Em todos os atributos químicos e físicos avaliados, houve a necessidade de um maior número de pontos de amostragem na pedoforma côncava e convexa em relação à pedoforma linear, tanto com a utilização da fórmula de Cline como com o alcance do semivariograma
(Figuras 2 e 3). Todos os atributos químicos e físicos tiveram mais de $84 \%$ dos pontos plotados na pedoforma côncava e convexa. Este resultado está de acordo com o comportamento das isolinhas (mais próximas) na pedoforma côncava e convexa, comprovando maior variabilidade espacial relativa dos atributos químicos e físicos (SOUZA et al., 2003). O maior número de pontos plotados na pedoforma côncava e convexa reforça a idéia de que, nestas pedoformas, as condições de fluxo de água superficial e lateral condicionam ambientes específicos que interferem nos processos pedogenéticos, favorecendo a maior variabilidade espacial dos atributos do solo. Esses resultados concordam com os obtidos por SOUZA et al. (2003), os

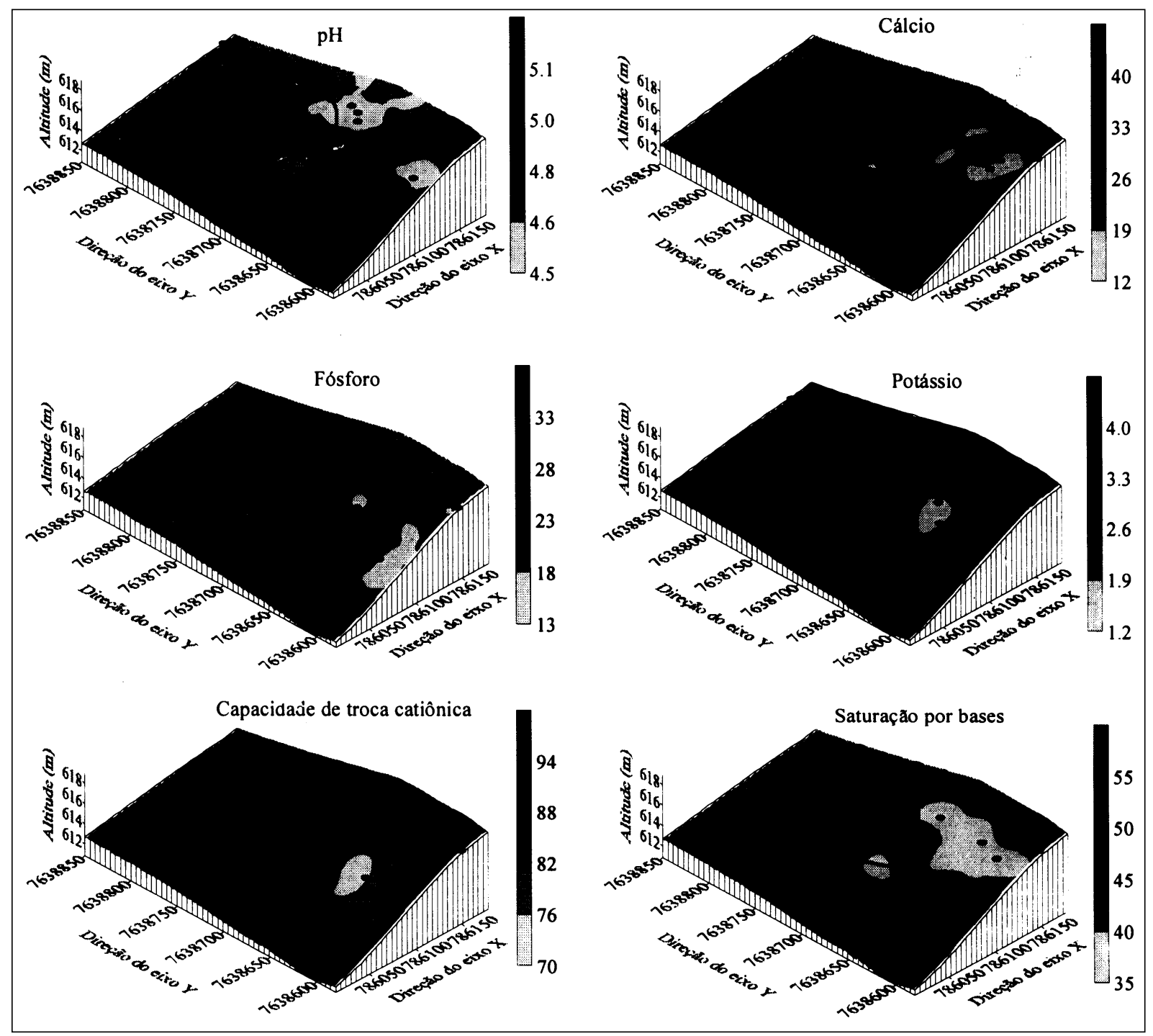

Figura 2 - Mapas da distribuição espacial e esquema amostral otimizado (pontos em preto) para as variáveis pH, cálcio $\left(\mathrm{mmol}_{\mathrm{c}} \mathrm{dm}^{-3}\right)$, fósforo $\left(\mathrm{mg} \mathrm{dm}^{-3}\right)$, potássio $\left(\mathrm{mmol}_{\mathrm{c}} \mathrm{dm}^{-3}\right)$, capacidade de troca catiônica $\left(\mathrm{mmol}_{\mathrm{c}} \mathrm{dm}^{-3}\right)$ e saturação por bases $(\%)$, conforme recomendação do programa de otimização Sanos 0.1 (sugestão de plotagem pelo alcance do semivariograma).

Ciência Rural, v.36, n.3, mai-jun, 2006. 


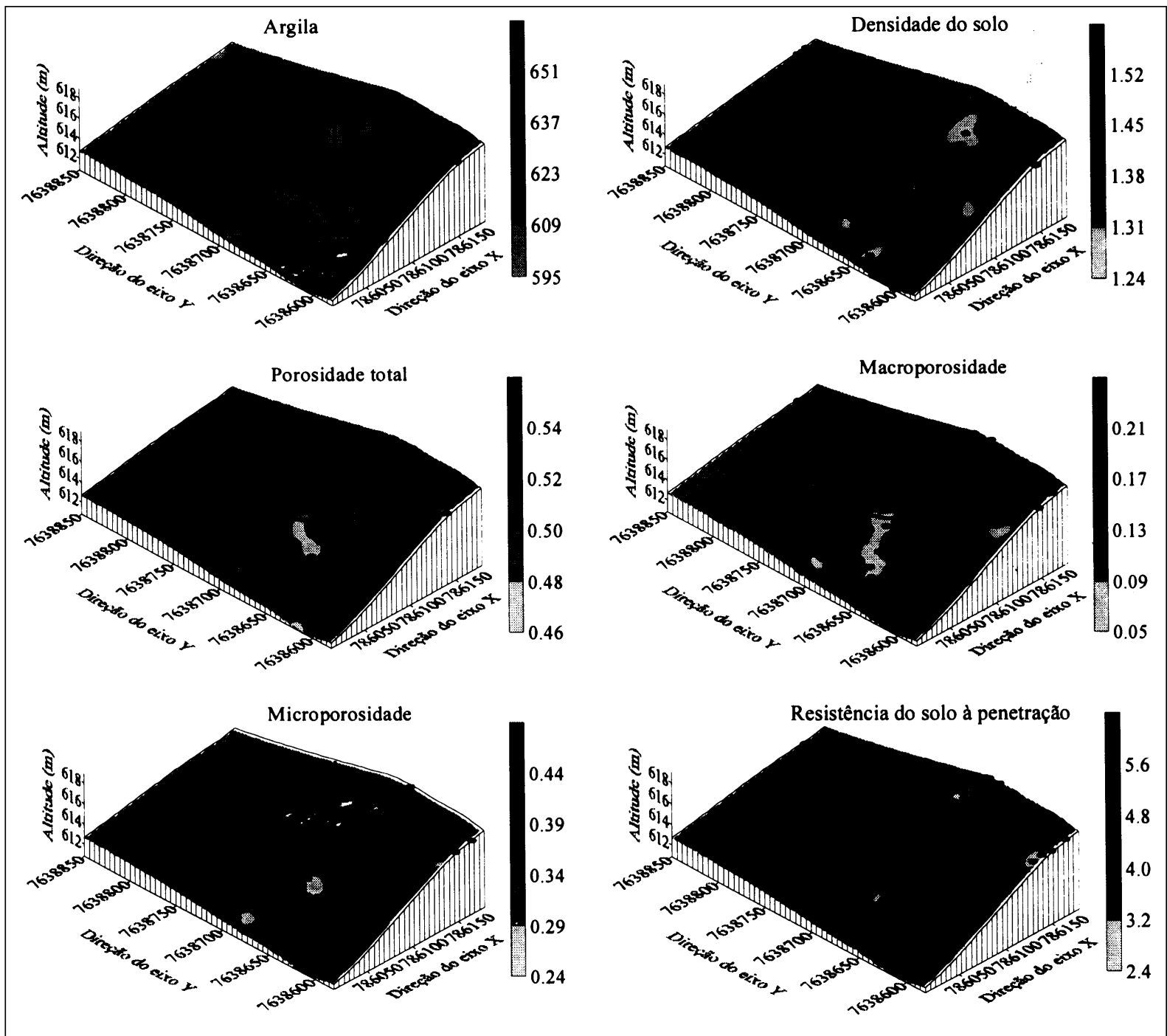

Figura 3 - Mapas da distribuição espacial e esquema amostral otimizado (pontos em preto) para as variáveis argila ( $\left.\mathrm{g} \mathrm{kg}^{-1}\right)$, densidade do solo $\left(\mathrm{kg} \mathrm{dm}^{-3}\right)$, porosidade total $\left(\mathrm{m}^{3} \mathrm{~m}^{-3}\right)$, macroporosidade $\left(\mathrm{m}^{3} \mathrm{~m}^{-3}\right)$, microporosidade $\left(\mathrm{m}^{3} \mathrm{~m}^{-3}\right)$ e resistência do solo à penetração $(\mathrm{MPa})$, conforme recomendação do programa de otimização Sanos 0.1 (sugestão de plotagem pelo alcance do semivariograma).

quais encontraram maior variabilidade da erosão na pedoforma côncava.

Um dos aspectos relevantes do programa Sanos 0.1 é a plotagem de pontos em locais de real necessidade, já que os cálculos são realizados com base nas coordenadas geográficas (GROENIGEN et al., 1999). SOUZA et al. (2003), estudando a influência da pedoforma na variabilidade espacial de atributos do solo sob cultivo de cana-de-açúcar, observaram que pequenas variações na pedoforma condicionam variabilidade diferenciada em relação aos atributos químicos e granulométricos, e que a variabilidade espacial foi maior na pedoforma côncava do que em relação à linear.
Os mapas de otimização de amostragem possibilitam um melhor entendimento do padrão de distribuição espacial, permitindo definir diferentes zonas de manejo (MONTANARI et al., 2005). Estes mapas podem ser de grande utilidade no planejamento experimental e são úteis também como ferramenta nos programas de agricultura de precisão, uma vez que o número de amostras a serem coletadas representa um elevado custo para esses programas (McBRATNEY \& WEBSTER, 1983).

Recomenda-se o uso do alcance do semivariograma para determinar o número de amostras que devem ser coletadas para os atributos químicos e físicos, de acordo com a escala de estudo. Para garantir a dependência espacial, os pontos devem ser coletados 
a uma distância equivalente à metade do alcance. No caso de não manter a dependência espacial, os pontos devem ser coletados a uma distância equivalente a duas vezes o alcance e, na pedoforma côncava e convexa, deve-se coletar um maior número de pontos.

\section{CONCLUSÕES}

Os atributos químicos e físicos têm mais de $84 \%$ dos pontos plotados na pedoforma côncava e convexa em relação a pedoforma linear. O maior número de pontos otimizados pelo programa Sanos for Windows 0.1 indica que pedoforma côncava e convexa apresenta maior variabilidade espacial para os atributos químicos e físicos do que a pedoforma linear.

\section{AGRADECIMENTOS E APRESENTAÇÃO}

À Fundação de Amparo à Pesquisa do Estado de São Paulo (FAPESP), pela concessão de bolsa ao pesquisador Souza.

Parte da Tese de Doutorado do primeiro autor, financiado pela Fundação de Amparo à Pesquisa do Estado de São Paulo (FAPESP)

\section{REFERÊNCIAS}

CAMBARDELLA, C.A. et al. Field-scale variability of soil properties in Central Iowa Soils. Soil Science Society of America Journal, Madison, v.58, n.5, p.1501-1511, 1994.

CLINE, M.G. Principles of soil sampling. Soil Science, Baltimore, v.58, n.2, p.275-288, 1944.

EMPRESA BRASILEIRA DE PESQUISA AGROPECUÁRIA EMBRAPA. Centro Nacional de Pesquisa de Solos (Rio de Janeiro, RJ). Manual de métodos de análise de solo. 2.ed. Rio de Janeiro, 1997. 212p. (Documentos, 1).

EMPRESA BRASILEIRA DE PESQUISA AGROPECUÁRIA EMBRAPA. Centro Nacional de Pesquisa de Solos. Sistema Brasileiro de Classificação de Solos. Rio de Janeiro, 1999. $412 \mathrm{p}$.

GROENIGEN, van J.W. et al. Contrained optmisation of soil sampling for minimisation of the kriging variance. Geoderma, Amsterdam, v.87, n.3-4, p.239-259, 1999.

ISAAKS, E.H.; SRIVASTAVA, R.M. An introduction to applied geoestatistics. New York: Oxford University, 1989. $561 \mathrm{p}$.

KRAVCHENKO, A.N.; BULLOCK, D.G. Correlation of corn and soybean yield with topography and soil properties. Agronomy Journal, Madison, v.75, n.1, p.75-83, 2000.

LARK, R.M. Designing grids from imprecise information on soil variability, an approach based on the fuzzy kriging variance. Geoderma, Amsterdam, v.98, n.1-2, p.35-39, 2000.
McBRATNEY, A.B.; WEBSTER, R. How many observations are needed for regional estimation of soil properties? Soil Science, Baltimore, v.135, n.3, p.177-183, 1983.

MONTANARI, R. et al. Forma da paisagem como critério para otimização amostral de latossolos sob cultivo de cana-de-açúcar. Pesquisa Agropecuária Brasileira, Brasília, v.40, n.1, p.69$77,2005$.

RAIJ, van B. et al. Recomendações de adubação e calagem para o Estado de São Paulo. 2.ed. Campinas: Instituto Agronômico/Fundação IAC, 1997. 285p. (Boletim Técnico, 100)

RAIJ, van B. et al. Análise química para avaliação da fertilidade de solos tropicais. Campinas: Instituto Agronômico, 2001. 285p.

ROBERTSON, G.P. $\mathrm{GS}^{+}$: Geostatistics for the environmental sciences (version 5.1 for windows). Plainwell: Gamma Design Software, 1998. 152p.

SANTOS, H.L.; VASCONCELLOS, C.A. Determinação do número de amostras de solo para análise química em diferentes condições de manejo. Revista Brasileira de Ciência do Solo, Campinas, v.11, n.1, p.97-100, 1987.

SCHLOTZHAVER, S.D.; LITTELL, R.C. SAS: system for elementary statistical analysis. 2.ed. Cary, 1997. $905 \mathrm{p}$.

SILVEIRA, P.M.; CUNHA, A.A. Variabilidade de micronutrientes, matéria orgânica e argila de um latossolo submetido a sistemas de preparo. Pesquisa Agropecuária Brasileira, Brasília, v.37, n.9, p.1325-1332, 2002.

SOUZA, L.S. et al. Variabilidade de propriedades físicas e químicas do solo em um pomar cítrico. Revista Brasileira de Ciência do Solo, Viçosa, v.21, n.3, p.367-372, 1997.

SOUZA, C.K et al. Influência do relevo na variação anisotrópica dos atributos químicos e granulométricos de uma latossolo em Jaboticabal-SP. Engenharia Agrícola, Jaboticabal, v.23, n.3, p.486-495, 2003.

SOUZA, Z.M. et al. Variabilidade espacial de atributos físicos de um Latossolo Vermelho sob cultivo de cana-de-açúcar. Revista Brasileira de Engenharia Agrícola Ambiental, Campina Grande, v.8, n.1, p.51-58, 2004.

SURFER for windows. Realese 7.0. Contouring and 3D surface mapping for scientist's engineers. User's guide. New York: Golden software, 1999. 619p.

STOLF, R. Teoria e teste experimental de fórmulas de transformação dos dados de penetrômetro de impacto em resistência do solo. Revista Brasileira de Ciência do Solo, Campinas, v.15, n.3, p.229-235, 1991.

TROEH, F.R. Landform equations fitted to contour maps. American Journal Science, New Haven, v.263, n.3, p.616$627,1965$. 